\title{
The effect of indomethacin, myeloperoxidase, and certain steroid hormones on bactericidal activity: an ex vivo and in vivo experimental study
}

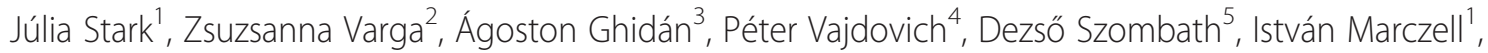
Szabolcs Várbíró ${ }^{6}$, Elek Dinya ${ }^{7}$, Tibor Magyar², Zsolt Tulassay ${ }^{1}$, Béla Székács ${ }^{1}$, Károly Nagy ${ }^{3}$, Károly Rácz and Gábor Békési $i^{*}$

\begin{abstract}
Background: The role of myeloperoxidase (MPO) is essential in the killing of phagocytosed bacteria. Certain steroid hormones increase MPO plasma concentration. Our aim was to test the effect of MPO, its inhibitor indomethacin, and certain steroid hormones on bactericidal activity.

Methods: Human polymorphonuclear leukocytes (PMN) were incubated with opsonised Escherichia coli and either MPO, indomethacin, estradiol, or hydrocortisone. Intracellular killing capacity was evaluated with UV microscopy after treatment with fluorescent dye. Next, an in vivo experiment was performed with nine groups of rats: in the first phase of the study indomethacin treatment and Pasteurella multocida infection (li), indomethacin treatment without infection (10), untreated control with infection (Mi) and untreated control without infection (M0); in the second phase of the study rats with infection and testosterone treatment (NT), castration, infection and testosterone treatment $(\mathrm{CT})$, castration, infection and estradiol treatment (CE), non-castrated infected control (NO), and castrated infected control (CO). After treatment bacteria were reisolated from the liver and heart blood on agar plates, and laboratory parameters were analyzed. For the comparison of laboratory results ANOVA or Kruskal-Wallis test and LSD post hoc test was used.
\end{abstract}

Results: Indomethacin did not have a remarkable effect on the bacterial killing of PMNs, while the other compounds increased bacterial killing to various degrees. In the animal model indomethacin and infection caused a poor clinical state, a great number of reisolated bacteria, elevated white blood cell (WBC) count, decreased C-reactive protein (CRP) and serum albumin levels. Testosterone treatment resulted in less bacterial colony numbers in group NT, but not in group CT compared to respective controls (NO, CO). Estradiol treatment (CE) decreased colony numbers compared to control (CO). Hormone administration resulted in lower WBC counts, and in group CE, a decreased CRP.

Conclusions: MPO, estradiol, and hydrocortisone improve bacterial killing activity of PMNs. Indomethacin treatment and castration weaken immune responses and clinical state of infected rats, while testosterone and estradiol have a beneficial effect.

Keywords: Bacterial killing activity, Infection, Myeloperoxidase, Indomethacin, Testosterone, Estradiol, Hydrocortisone

\footnotetext{
* Correspondence: bekesi.gabor@med.semmelweis-univ.hu

${ }^{1}$ Faculty of Medicine, 2nd Department of Internal Medicine, Semmelweis

University, 46. Szentkiralyi u., H-1088 Budapest, Hungary

Full list of author information is available at the end of the article
} 


\section{Background}

Free radicals are very reactive compounds with one or more unpaired electrons on their outer orbitals. They are of great importance in the bacterial killing role of macrophages. The most important reactive oxygen radical is the superoxide anion with limited reactivity, but it can be converted into other more reactive radicals. Its main source is NADPH, which is oxidased by NADPH oxidase (NOX). Superoxide anion can be converted into hydrogen peroxide $\left(\mathrm{H}_{2} \mathrm{O}_{2}\right)$ by superoxide dismutase (SOD), and the produced $\mathrm{H}_{2} \mathrm{O}_{2}$ is used in the oxidation of chloride ions to hypochlorous acid $(\mathrm{HOCl})$ with the catalyzation of myeloperoxidase (MPO). $\mathrm{HOCl}$ deploys bactericidal activity on the bacteria ingested in the phagosome. Additionally, chloramines generated by $\mathrm{HOCl}$ reacting with phagosomal proteins also contribute to bacterial killing, but the full consequences of this are not yet clear [1,2].

However, under certain circumstances an excess of these oxidizing species can overwhelm local antioxidant defence and lead to oxidative stress (OS) and tissue injury that are implicated in the pathogenesis of diseases like atherosclerosis, emphysema, acute respiratory distress syndrome, reperfusion injury, malignancy, diabetes mellitus, and Alzheimer's disease [2].

The tissues are protected against free radicals by antioxidant enzymes (such as SOD, catalase, glutathione reductase, $\alpha_{1}$-antitripsin), peptides with thiol groups (glutathione, thioredoxin family) and nutritional antioxidants (vitamin $\mathrm{C}$ and $\mathrm{E}$, carotenoids, trace elements) $[2,3]$. Certain steroid hormones also play a role in antioxidant defence through various mechanisms. In our previous work we demonstrated that cortisol, 17-ß-oestradiol $\left(E_{2}\right)$, progesterone, and testosterone decreased the superoxide release from human PMNs, while aldosterone and cortexolone, the precursor of cortisol did not have such property [4].

In the literature the most extensively studied steroid hormone is $E_{2}$. It enhances the cellular anti-oxidative defence molecules, reduces the production of reactive oxygen species (ROS), activates endothelial, inducible and neuronal nitric oxide synthase, and neutralizes the excess ROS in various cell types [5].

The mechanism of antioxidant action of hydrocortisone is scantly studied in the literature. It is mainly referred to as the main biomarker of stress, which leads to oxidative changes [6]. However, a correlation between plasma hydrocortisone and $\mathrm{Cu} / \mathrm{Zn}$ SOD activity has been recorded in rhesus monkeys, and both have been found to have a similar diurnal rhythm [7]. Other glucocorticoids have both glucocorticoid receptor mediated genomic and a rapid non-genomic antioxidant effect $[8,9]$.

The antioxidant effect of testosterone is ambiguous in the literature. In one study it showed a receptormediated antioxidant effect in vitro on cerebellar granule cells [10], but according to others it caused a decrease in the activity of antioxidant enzymes and led to lipid peroxidation in the prostate and testis of rodents $[11,12]$.

MPO has also been reported to have antioxidant capacity despite its known free radical producing activity. It contributes to the termination of free radical production in PMNs $[13,14]$, and the incubation of human PMNs with $\mathrm{MPO}$ and $\mathrm{NaClO}$, the end-product of the MPO catalyzed peroxidation, yielded a decrease in superoxide release, probably by inhibiting NOX $[14,15]$. In fact, it has been found, that MPO release and activity in PMNs can be enhanced by certain steroids, like $E_{2}$, testosterone, and prednisolone. Thus, the antioxidant effect of these steroid hormones might be carried out at least in part by the elevation of MPO activity and release [14-16]. On the other hand, the MPO inhibitor indomethacin, a nonsteroidal anti-inflammatory drug, a nonselective cyclooxygenase inhibitor increases free radical production in PMNs $[14,17]$. This could mean a beneficial effect in the bactericidal activity of PMNs.

In our present studies we aimed to evaluate the effect of indomethacin on ex vivo and in vivo bactericidal function. We also tested MPO, $E_{2}$, and hydrocortisone on antibacterial capability of human PMNs, and the effect of indomethacin, testosterone, and $\mathrm{E}_{2}$ on an in vivo rat model. Our ultimate aim was to evaluate if indomethacin can be useful as an adjuvant therapy in septic patients. Since the two experimental models are different, and sex steroids have various effects on many participants of the immune system besides PMNs, the comparison of the results of the two experiments needs caution.

\section{Methods}

Ex vivo effect of indomethacin, MPO, estradiol, and hydrocortisone on the bactericidal activity of human isolated PMNs

\section{Isolation of PMNs}

Venous blood was drawn from 6 male and 5 female donors, aged 23-40 years. All volunteers were non-smokers, took no medications, did not suffer from any known disease and consented to participation. The blood was taken into EDTA tubes between 8-9 a.m. after an overnight fasting. PMNs were separated within 2 hours of blood drawing with the following method. The blood was applied to Histopaque (Sigma, 1077-1) in layers for the sedimentation of red blood cells and put aside for an hour. Then it was transferred to $63 \%$ and $72 \%$ Percoll (Sigma, P-1644) and centrifuged for $25 \mathrm{~min}$ at a rate of $300 \times \mathrm{g}$ at $20^{\circ} \mathrm{C}$. Granulocytes thus separated were buffer-washed twice and centrifuged with $220 \times$ g. Cells aggregated at the bottom of the tube were re-suspended in a few milliliters of Hank's buffer salt solution (Sigma, H-8264), then counted using Turk's solution. The cell concentration of the suspension was adjusted to 5 million cells $/ \mathrm{ml}$. 


\section{E. coli opsonisation}

Escherichia coli O111:K58 strain was used. The bacterial strain was cultivated on blood agar plates overnight at $37^{\circ} \mathrm{C}$. A loopful of bacteria was suspended in $200 \mu \mathrm{l}$ of Hank's buffer. After adding 4 drops of antibody to the suspension it was incubated for $30 \mathrm{~min}$ at $37^{\circ} \mathrm{C}$. The antibody was specifically produced for $E$. coli O111:K58 strain by the National Centre of Epidemiology, Budapest, Hungary.

\section{Intracellular bacterial killing}

$400 \mu \mathrm{l}\left(2 \times 10^{6}\right)$ of $5 \times 10^{6} / \mathrm{ml}$ PMNs were incubated for 2 hours at $37^{\circ} \mathrm{C}$ in a water bath either with $0.01 \mathrm{mg} / \mathrm{ml}$ indomethacin (Sigma, I7378-5G), $71 \mathrm{ng} / \mathrm{ml}$ MPO (Merck, 475911), $10^{-8}$ mol 17ß-oestradiol (Sigma, E8875) or $10^{-8}$ mol hydrocortisone (Sigma, H4001). Control cells were incubated without any treatment. After incubation, PMNs were mixed with $2 \times 10^{7}$ opsonised E. coli cells, and the compounds were kept in the water bath for further $30 \mathrm{~min}$. After this, 1-1 ml of ice-cold Hank's buffer was added to each compound, and they were centrifuged for $7 \mathrm{~min}$ at $6000 \mathrm{rpms}$. After having removed the aliquots, the pellets were dyed with $200 \mu \mathrm{l}(1.44 \mathrm{ml} / 100 \mathrm{ml}$ Hank's buffer) acridine orange (Sigma, A6014-10G) for one minute. Then again $1 \mathrm{ml}$ cold Hank's buffer was added and the mixtures were centrifuged for $5 \mathrm{~min}$ at 10,000 rpms. The aliquots were removed and bacterial killing was examined in the pellets. Acridine orange stains only dead bacteria, which fluoresce in orange when excited by ultraviolet light. The bacterial killing effect was evaluated visually under UV microscope (Leica, DMRB DIC). Several fields of vision were examined for each sample in order to find the true amount of dead bacteria. To express intracellular killing effect of the various drugs a scoring system from $0-5$ was set up, where 0 indicates no bacterial killing and 5 indicates a hypothetical maximal killing. The results of bacterial killing were also expressed as percentages compared to the control, which is considered $100 \%$. From the results of parallel measurements an average was calculated.

\section{Effect of indomethacin, testosterone, and estradiol on the bactericidal activity in vivo in rats}

The in vivo experiments were carried out in two phases. SPF adult male Wistar rats $\{\mathrm{Crl}$.(Wi)Br. $\}$ weighing 120 170 grams were used for both experiments. In the first phase animals were kept in groups of eight, had access to conventional rat food (Ssniff R-Z, Spezialdiaten $\mathrm{GmbH}$, Soest, Germany) and fresh drinking water ad libitum. The rats were given the following treatments through a feeding tube for five days, once daily: groups $\mathrm{M} 0$ and Mi: $0.8 \mathrm{ml}$ of $1 \%$ methylcellulose solution; groups I0 and Ii: $0.8 \mathrm{mg}$ indomethacin $[0.8 \mathrm{ml}$ of $1 \mathrm{mg} / \mathrm{ml}$ indomethacin (Sigma, 865500-5G) dissolved in 1\% methylcellulose].
In the names of the groups, the uppercase letter refers to the treatment ( $\mathrm{M}=$ methylcellulose, $\mathrm{I}=$ indomethacin), " 0 " means no infection and "i" refers to infection.

On the 3rd day of treatment rats in groups Mi and Ii were infected with Pasteurella multocida ssp. septica. Prior to infection, Pasteurella multocida ssp. septica (isolate P964) was stored in $1 \mathrm{ml}$ of skimmed milk at $-70^{\circ} \mathrm{C}$. The isolate was streaked onto Columbia agar plate (Merck, Darmstadt, Germany) containing 5\% (v/v) defibrinated sheep's blood and cultivated at $37^{\circ} \mathrm{C}$ for 24 hours. Single colonies were passed and cultivated again at $37^{\circ} \mathrm{C}$ for 24 hours. Bacterium culture was washed with $2 \mathrm{ml}$ saline. Rats were infected with a subcutaneous injection of $0.2 \mathrm{ml}$ of $6 \times 10^{8}$ colony forming units $(\mathrm{CFU}) / \mathrm{ml}$ bacteria diluted in physiological saline $\left(1.2 \times 10^{8}\right.$ germs/animal). Uninfected animals got $0.2 \mathrm{ml}$ saline on the same route.

On the 5th day of treatment animals were anaesthetized with diethyl ether and exsanguinated through the abdominal aorta. Blood was collected for laboratory analysis of inflammatory markers and hormone levels. Blood count, serum proteins, CRP, serum testosterone and estradiol were determined with well established automated laboratory methods used in clinical practice at the Szent Istvan University, Faculty of Veterinary Science, Department and Clinic of Internal Medicine, Budapest.

Isolation of the infective agent was attempted from each liver and heart blood. A loopful of sample was streaked onto Columbia blood agar (CBA) and plates were incubated at $37^{\circ} \mathrm{C}$ for 24 hours. The number of CFUs was evaluated and isolates were classified as "none", "1-10 colonies", "dense, but separate" and "confluent" colony patterns according to the density of the culture. The uninfected groups were negative for culturing while the majority of infected animals gave positive result with variable density. Microbiological examinations were carried out at the Institute for Veterinary Medical Research of the Hungarian Academy of Sciences, Budapest.

In the second in vivo phase 30 rats were used and all of the animals were infected and the effects of hormone treatments were examined. Animals were kept as described previously. Five groups of 6 were created, and 18 rats were castrated. After a 10-day recovery period the following treatments were given for seven days, twice daily (8:30 a.m., 6 p.m.) in a subcutaneous injection: group N0: $0.35 \mathrm{ml}$ propylene glycol, not castrated; group NT: $0.35 \mathrm{ml}$ of $800 \mu \mathrm{g} / \mathrm{ml}$ testosterone dissolved in propylene glycol, not castrated; group C0: $0.35 \mathrm{ml}$ propylene glycol, castrated; group CT: $0.35 \mathrm{ml}$ of $800 \mu \mathrm{g} / \mathrm{ml}$ testosterone dissolved in propylene glycol, castrated; group CE: $0.35 \mathrm{ml}$ of $20 \mu \mathrm{g} / \mathrm{ml} 17-\beta$-estradiol dissolved in propylene glycol, castrated. In the names of the groups " $\mathrm{N}$ " and "C" mean not castrated and castrated, respectively; " 0 ", "T" and " $\mathrm{E}$ " refer to no treatment, testosterone and estradiol treatment, respectively. 
On the 4th day of treatment all animals were infected with a subcutaneous injection of $0.2 \mathrm{ml}$ of $2.4 \times 10^{9} \mathrm{CFU} / \mathrm{ml}$ Pasteurella multocida ssp. septica diluted in physiological saline, as described above $\left(4.8 \times 10^{8}\right.$ germs/animal $)$. On the 7 th day of treatment animals were anaesthetized and exsanguinated, laboratory and microbiological examinations were carried out as in the previous experiment.

Both experiments were approved by the university ethical committee.

\section{Statistical analysis}

The Statistica software was used for all analyses. For the comparison of laboratory results of rats ANOVA or Kruskal-Wallis test and LSD post hoc test was used. $P<0.05$ was considered statistically significant.

\section{Results}

Ex vivo effect of indomethacin, MPO, estradiol, and hydrocortisone on the bactericidal activity of human isolated PMNs

The ex vivo effect of indomethacin, MPO, estradiol and hydrocortisone on bacterial killing are shown in Figure 1. Due to technical problems not all experiments gave valuable results, thus the number of donors (n) is variable among treatment groups. Indomethacin did not have a remarkable effect in either direction, using either scale. The three other compounds seem to increase bacterial killing of PMNs to various degrees: estradiol is the most efficient, while hydrocortisone has the least activity.

Effect of indomethacin, testosterone, and estradiol on the bactericidal activity in vivo in rats

In the first phase of our in vivo studies 1-1 rats were wasted in the infected groups (Mi, Ii), and 2 in the uninfected group treated with indomethacin (group I0) on the 4th day of treatment, i.e. the day after the infection. Animals in groups I0 and Ii (treated with indomethacin, without and with infection) were weak and faint. Ascites was found in two rats in group I0 and one in group Ii. After the reisolation of $P$. multocida from liver and cardiac blood of infected animals, colony patterns were evaluated (Table 1, Figure 2). The greatest number of bacteria could be reisolated from the animals in group Ii, with confluent colonies in 11 samples, $v s 3$ samples in group Mi. In group Ii none of the samples gave a negative reisolation, however, in three samples in group Mi no colonies were reisolated. The laboratory findings (Table 1) showed that WBC count was significantly higher in group Ii than in groups I0 and $\mathrm{Mi}$, with higher neutrophil and lower lymphocyte ratios in both indomethacin-treated groups (IO, Ii). In both groups I0 and Ii anaemia was found, with lower red blood cell (RBC), haemoglobin (HGB) and haematocrit (HCT) levels compared to the other groups. Albumin levels were also lower in groups I0 and Ii. CRP was increased in group Mi compared to uninfected groups, however, in group Ii CRP decreased. Laboratory analysis could not be carried out in some samples ( 2 in group M0, 1 in group I0, 1 in group Mi) due to clotting or insufficient amount of blood.

In the second phase of the in vivo experiments, during the 10 days of recovery after castration, weight gain of castrated animals was less than that of the not castrated ones, otherwise they were recovering fine. One animal in group $\mathrm{C} 0$ was wasted before the infection without any clinical antecedent. The section did not reveal any cause, and liver, heart blood and lung tissue cultures gave negative results. After the induction of infection all animals were depressed and faint, especially in group $\mathrm{C} 0$. The results of the reisolation of $P$. multocida are shown in Table 2 and Figure 3a-b. In group NT fewer bacteria could be cultured compared to the untreated (N0) group. In group $\mathrm{CT}$ more bacteria were reisolated than in group NT and C0. Group CE had similar results as group NT.

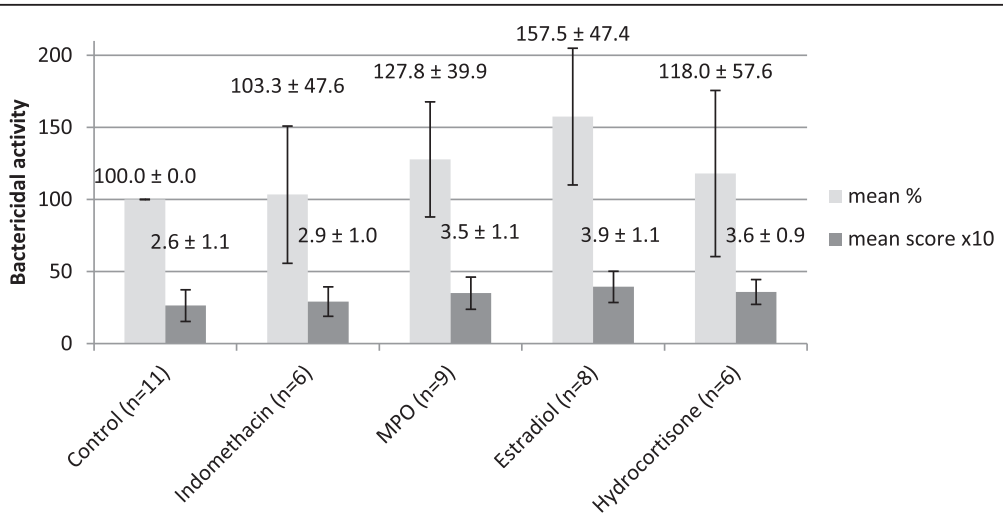

Figure 1 The bactericidal activity of PMNs after indomethacin, myeloperoxidase (MPO), estradiol, and hydrocortisone treatment. Results are expressed as percentage of control (mean \pm SD) and as scores (mean \pm SD). For better visibility the scores were multiplied by 10 on the diagram. The error bars show standard deviation. 
Table 1 Results of the first phase of the animal study

\begin{tabular}{|c|c|c|c|c|c|c|c|}
\hline & 1. MO & 2. 10 & \multicolumn{2}{|l|}{ 3. Mi } & \multicolumn{2}{|l|}{ 4. Ii } & $p<0.05$ \\
\hline Treatment & None (methylcellulose) & Indomethacin & \multicolumn{2}{|c|}{ None (methylcellulose) } & \multicolumn{2}{|l|}{ Indomethacin } & \\
\hline Infection & No & No & Yes & & Yes & & \\
\hline Colony patterns: & & & Heart blood & Liver & Heart blood & Liver & \\
\hline None & & & 2 & 1 & 0 & 0 & \\
\hline 1-10 colonies & & & 3 & 2 & 2 & 1 & \\
\hline Dense, but separate & & & 1 & 4 & 1 & 1 & \\
\hline Confluent & & & 2 & 1 & 5 & 6 & \\
\hline Sample number for lab tests & 6 & 5 & 6 & & 7 & & \\
\hline WBC $\left(\times 10^{9} / 1\right)$ & $7.72 \pm 2.06$ & $5.09 \pm 3.53$ & $5.95 \pm 2.61$ & & $9.28 \pm 1.87$ & & 4 vs 2,3 \\
\hline Neutrophil (\%) & $18.00 \pm 4.53$ & $47.40 \pm 26.10$ & $22.83 \pm 5.64$ & & $30.83 \pm 9.30$ & & ns \\
\hline Lymphocyte (\%) & $80.00 \pm 4.36$ & $49.00 \pm 28.10$ & $73.67 \pm 6.47$ & & $64.50 \pm 9.22$ & & ns \\
\hline $\operatorname{RBC}\left(\times 10^{12} /\right)$ & $5.94 \pm 0.68$ & $3.86 \pm 1.52$ & $5.66 \pm 0.39$ & & $3.66 \pm 1.09$ & & 4 vs 1 \\
\hline HGB (g/dl) & $110.00 \pm 9.00$ & $73.40 \pm 29.20$ & $105.67 \pm 6.83$ & & $68.50 \pm 18.22$ & & 4 vs 1 \\
\hline $\mathrm{HCT}(\mathrm{I} / \mathrm{I})$ & $0.39 \pm 0.03$ & $0.26 \pm 0.11$ & $0.38 \pm 0.03$ & & $0.25 \pm 0.07$ & & 4 vs 1 \\
\hline Total protein (g/l) & $55.65 \pm 2.49$ & $52.20 \pm 4.65$ & $59.22 \pm 3.00$ & & $42.00 \pm 7.86$ & & 4 vs 3 \\
\hline Albumin (g/l) & $27.92 \pm 0.98$ & $22.88 \pm 3.13$ & $26.07 \pm 0.65$ & & $19.80 \pm 3.65$ & & 4 vs 1 \\
\hline Globulin (g/l) & $27.73 \pm 1.63$ & $29.32 \pm 2.79$ & $33.15 \pm 2.63$ & & $22.20 \pm 4.30$ & & 3 vs $1,2,4 ; 4$ vs 1,2 \\
\hline CRP (mg/dl) & $300.00 \pm 25.20$ & $306.60 \pm 32.90$ & $411.67 \pm 55.98$ & & $261.71 \pm 72.99$ & & 3 vs $1,2,4$ \\
\hline
\end{tabular}

The number of different $P$. multocida colony shapes and laboratory results (means $\pm \mathrm{SD}$ ). The last column shows the groups where significant differences were found. ns: not significant.

Laboratory findings of this phase of the study (Table 2) showed that WBC count was lower in group NT than in group NO, and in groups $\mathrm{CT}$ and $\mathrm{CE}$ than in group $\mathrm{C}$. CRP was lowest in group CE, and also group CT had a lower CRP than group $\mathrm{C} 0$, however, this did not reach significance. One blood sample in group CE was not sufficient for analysis.

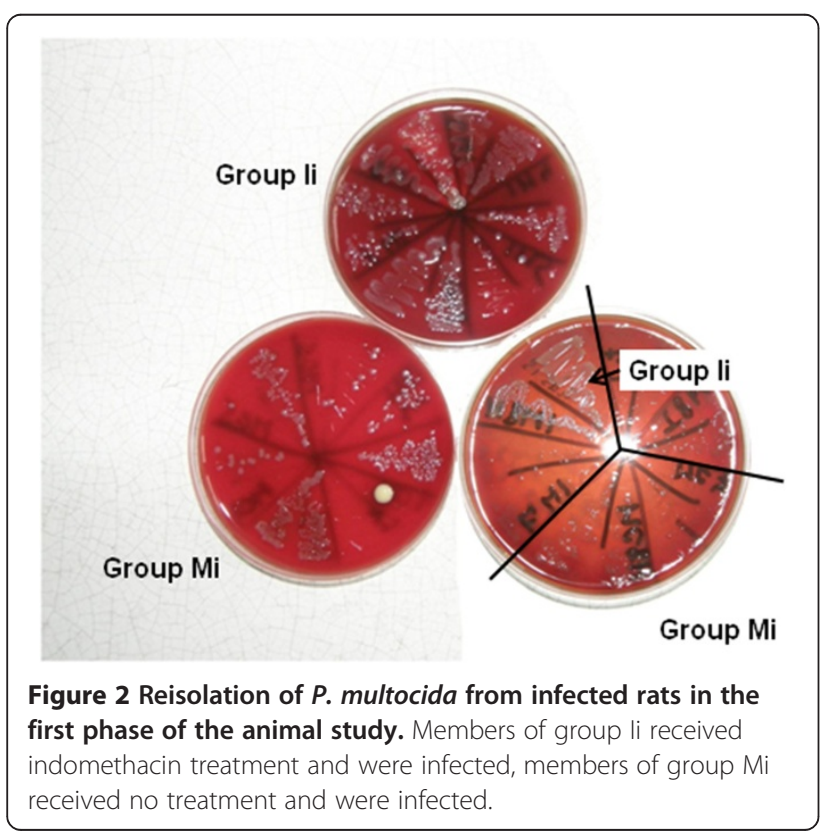

\section{Discussion}

In our ex vivo experiments we found that the MPO inhibitor indomethacin did not improve the bactericidal activity of human neutrophil granulocytes. Myeloperoxidase, which has a physiologic role in antibacterial defence, and antioxidant steroids, like estradiol and hydrocortisone have a variably positive effect on bactericidal activity. Although the donors were both males and females, we did not find sex-related differences in the bacterial killing of PMNs.

The results of our in vivo studies are also in accordance with these. The behaviour of the animals, the death rates, development of ascites, and most importantly the reisolation of bacteria all support the negative impact of indomethacin on the course of the P. multocida infection. Laboratory findings also show decreased coping capability of infected and indomethacin treated rats: higher white blood cell counts, increased neutrophil ratio, anaemia, decreased concentration of serum proteins (albumin, globulin, total protein) and CRP. Serum proteins, being mediators of the humoral immune system, give the base of the inflammatory response against microorganisms. Serum albumin is decreased in inflammatory diseases due to reduced hepatic synthesis [18]. CRP is an acute phase protein, that can influence multiple stages of inflammation and has both proinflammatory and antiinflammatory effect $[19,20]$. The collective decrease of these parameters implies a deteriorated bactericidal capacity. It is 
Table 2 Results of the second phase of the animal study

\begin{tabular}{|c|c|c|c|c|c|c|c|c|c|c|c|}
\hline & \multicolumn{2}{|l|}{ 1. No } & \multicolumn{2}{|l|}{ 2. NT } & \multicolumn{2}{|l|}{ 3. CO } & \multicolumn{2}{|l|}{ 4. $C T$} & \multicolumn{2}{|l|}{ 5. CE } & \multirow[t]{2}{*}{$p<0.05$} \\
\hline Castrated & No & & No & & Yes & & Yes & & Yes & & \\
\hline Treatment & None & & Testosterone & & None & & Testosterone & & Estradiol & & \\
\hline Infection & Yes & & Yes & & Yes & & Yes & & Yes & & \\
\hline Colony patterns: & Heart blood & Liver & Heart blood & Liver & Heart blood & Liver & Heart blood & Liver & Heart blood & Liver & \\
\hline None & 0 & 2 & 1 & 1 & 1 & 1 & 1 & 1 & 1 & 0 & \\
\hline 1-10 colonies & 2 & 1 & 4 & 3 & 2 & 1 & 0 & 0 & 4 & 3 & \\
\hline Dense, but separate & 2 & 2 & 0 & 2 & 0 & 2 & 1 & 2 & 1 & 3 & \\
\hline Confluent & 2 & 1 & 1 & 0 & 2 & 1 & 4 & 3 & 0 & 0 & \\
\hline Sample number for lab tests & 6 & & 6 & & 5 & & 6 & & 5 & & \\
\hline WBC $\left(\times 10^{9} / \mathrm{I}\right)$ & $10.70 \pm 4.18$ & & $5.97 \pm 3.22$ & & $8.26 \pm 4.62$ & & $3.61 \pm 2.14$ & & $2.03 \pm 1.05$ & & 1 vs 4,5 \\
\hline Neutrophil (\%) & $50.02 \pm 21.82$ & & $54.30 \pm 26.95$ & & $54.12 \pm 19.20$ & & $38.40 \pm 26.29$ & & $53.15 \pm 21.23$ & & ns \\
\hline Lymphocyte (\%) & $45.20 \pm 22.89$ & & $37.46 \pm 28.09$ & & $39.56 \pm 16.32$ & & $58.22 \pm 23.98$ & & $41.15 \pm 22.52$ & & ns \\
\hline $\mathrm{RBC}\left(\times 10^{12} / \mathrm{l}\right)$ & $6.63 \pm 0.32$ & & $6.44 \pm 0.45$ & & $5.99 \pm 0.47$ & & $5.41 \pm 0.86$ & & $5.95 \pm 0.21$ & & 4 vs 1,2 \\
\hline $\mathrm{HGB}(\mathrm{g} / \mathrm{dl})$ & $135.40 \pm 4.67$ & & $132.40 \pm 7.16$ & & $120.60 \pm 12.46$ & & $111.40 \pm 16.6$ & & $120.75 \pm 4.65$ & & 4 vs 1,2 \\
\hline HCT (I/I) & $0.41 \pm 0.02$ & & $0.40 \pm 0.03$ & & $0.36 \pm 0.03$ & & $0.32 \pm 0.05$ & & $0.35 \pm 0.02$ & & 4 vs 1,$2 ; 5$ vs 1 \\
\hline $\operatorname{PLT}\left(\times 10^{9} / \mathrm{l}\right)$ & $718.80 \pm 298.4$ & & $865.40 \pm 212.5$ & & $875.60 \pm 170$. & & $696.60 \pm 127$ & & $440.75 \pm 198.0$ & & 5 vs 2,3 \\
\hline Total protein (g/l) & $47.32 \pm 2.02$ & & $49.53 \pm 2.88$ & & $51.00 \pm 4.45$ & & $46.83 \pm 4.24$ & & $49.76 \pm 3.71$ & & ns \\
\hline Albumin (g/l) & $16.68 \pm 1.17$ & & $17.55 \pm 1.18$ & & $18.30 \pm 1.59$ & & $17.03 \pm 2.14$ & & $18.76 \pm 1.50$ & & ns \\
\hline Globulin (g/l) & $30.63 \pm 2.67$ & & $31.98 \pm 2.18$ & & $32.70 \pm 4.67$ & & $29.80 \pm 3.03$ & & $31.00 \pm 2.53$ & & ns \\
\hline CRP (mg/dl) & $375.30 \pm 64.54$ & & $371.58 \pm 33.56$ & & $363.30 \pm 23.90$ & & $329.42 \pm 52.2$ & & $149.60 \pm 131.7$ & & 5 vs $1,2,3,4$ \\
\hline Testosterone (nmol/l) & $21.62 \pm 16.08$ & & $54.87 \pm 1.55$ & & $0.87 \pm 0.31$ & & $41.82 \pm 12.10$ & & $0.68 \pm 0.00$ & & $\begin{array}{l}1 \text { vs } 2,3,4,5 ; 2 \text { vs } 3,5 ; \\
4 \text { vs } 3,5\end{array}$ \\
\hline Estradiol (pg/ml) & $113.44 \pm 30.62$ & & nd & & $151.75 \pm 13.12$ & & nd & & $867.40 \pm 558.1$ & & 5 vs 1,3 \\
\hline
\end{tabular}

The number of different $P$. multocida colony shapes and laboratory results (means $\pm \mathrm{SD}$ ). The last column shows the groups where significant differences were found. ns: not significant, nd: not determined.

interesting to note, that indomethacin tends to lower serum albumin, even without infection. As $90-99 \%$ of indomethacin is bound to albumin in the bloodstream, reduced albumin levels lead to an increased concentration of free indomethacin, and thus an even worse antibacterial activity during infection [21].

As expected, castration led to weak clinical state, however, in the untreated groups, castration did not worsen reisolation and laboratory parameters after infection with $P$. multocida. On the other hand, testosterone treatment of castrated animals seems to cause anaemia and weaker bactericidal capacity when compared to noncastrated and testosterone-treated rats, but better WBC and CRP results when compared to the castrated, untreated group. Testosterone treatment of non-castrated animals resulted in stronger bactericidal effect (less reisolated bacteria) and lower WBC count after infection compared to the non-castrated, untreated group. Taken together, testosterone seems to improve the levels of inflammatory parameters compared to the respective control.

The effect of testosterone on the immune system has been studied by others with various results. It has been shown that testosterone leads to delayed acquired immunity by directly affecting $\mathrm{T}$ or $\mathrm{B}$ cells [22], reducing NK cell activity [23], limiting lymphocyte proliferation, and decreasing immunoglobulin and cytokine production [24-26]. Testosterone has been shown to impair TNF and NO production by macrophages, and to suppress NF- $\mathrm{kB}$ signal transduction, which has a substantial role in mediating proinflammatory cytokine production. It can also enhance the production of anti-inflammatory cytokines like IL-10 and IL-4 [23]. However, in another study elevated proinflammatory cytokines such as TNF- $\alpha$, IL- 6 and IL-1- $\beta$ were found in male rats compared to females [27].

Estradiol treatment of castrated rats seems to enhance bactericidal defence mechanisms most, as reisolation of $P$. multocida showed the lowest colony numbers, and decreased CRP and WBC count could mean that the infection was less severe due to estradiol pre-treatment. $E_{2}$ also led to lower platelet count, thus decreasing the risk of thromboembolism in these animals.

In the literature $\mathrm{E}_{2}$ has been shown to have a dual effect according to its concentration. Low doses of $E_{2}$ enhance 

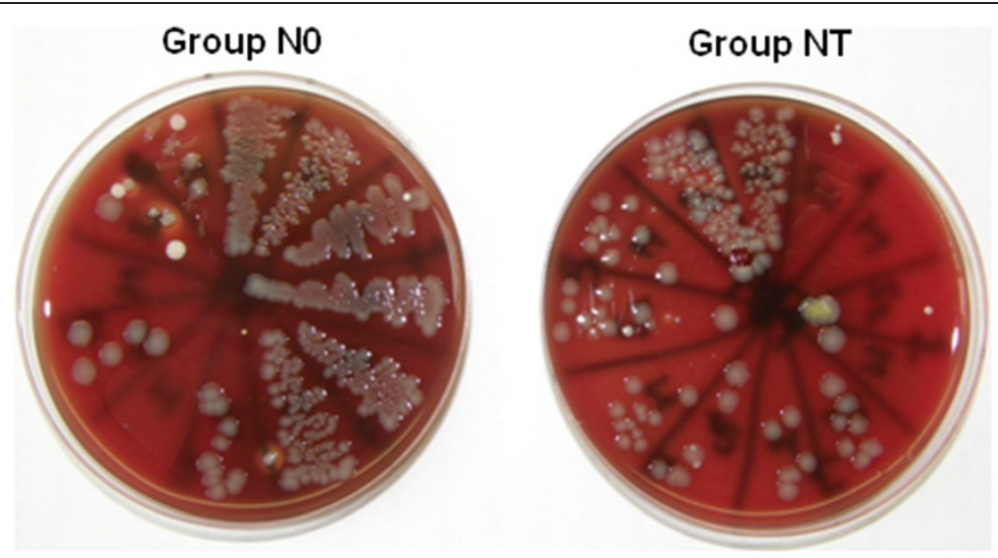

a

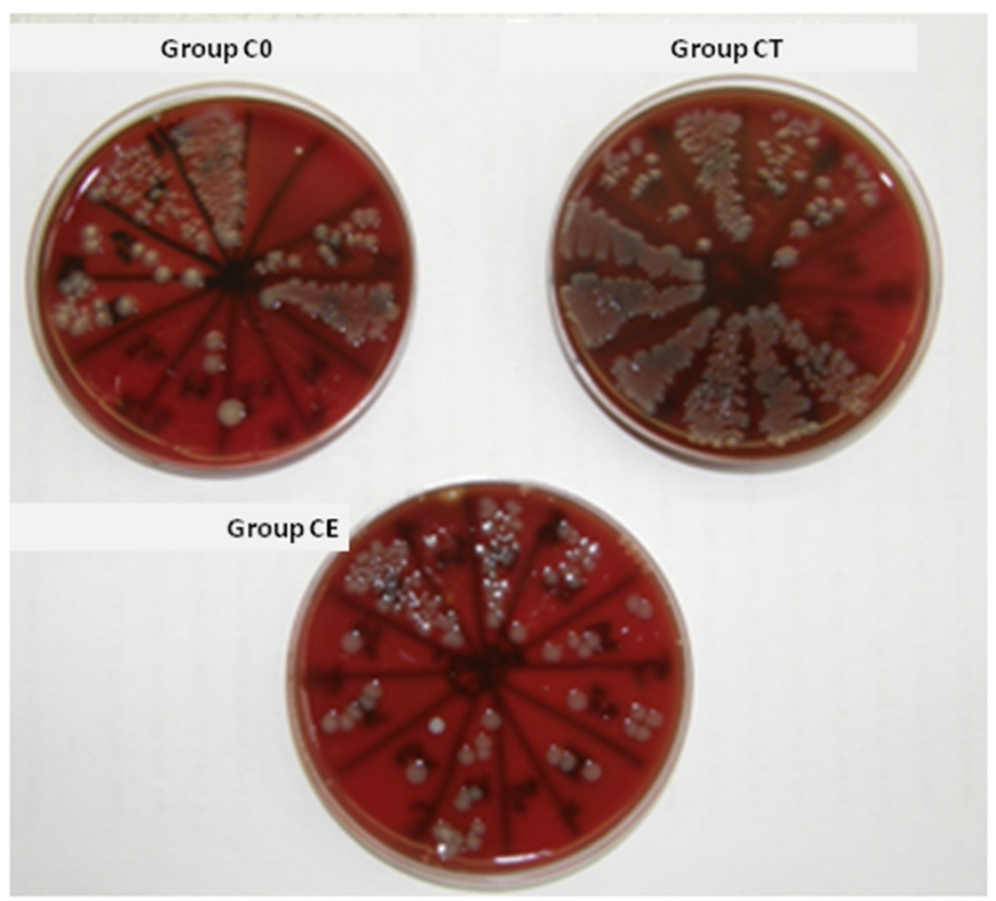

b

Figure 3 Reisolation of $P$. multocida from infected rats in the second phase of the animal study. a) Members of group N0 received no treatment besides infection, group NT received testosterone treatment. b) Members of group CO were castrated, but did not receive treatment besides infection, members of groups CT and CE were castrated and received either testosterone or estradiol treatment, respectively.

the production of proinflammatory cytokines (IL-1, IL-6, TNF- $\alpha$ ) and T helper cell type 1 (Th1) responses, while high or sustained $E_{2}$ concentrations are associated with an increased susceptibility to infections [28], reduced proinflammatory cytokine production and enhanced Th2 responses and humoral immunity [23,29]. This effect is thought to be mediated by estrogen receptor signalling, which suppresses NF- $\mathrm{kB}$ activity [30]. $\mathrm{E}_{2}$ can inhibit the proliferation of mononuclear leukocytes and reduce NK cell cytotoxicity [26]. In a study with steers, administration of high doses of $\mathrm{E}_{2}$ did not affect total and differential
WBC count, lymphocyte blastogenesis and neutrophil function [31]. When given to castrated mice, $E_{2}$ did not exhibit immunosuppressive effects [22], but another study concluded that intracellular bacterial killing in PMNs is impaired by physiological levels of $E_{2}$, probably due to a decrease in MPO activity [32,33].

According to our previous results, antioxidant steroids increase MPO activity, which leads to an elevation of the concentration of hypochlorite, the end product of MPO induced peroxidation [14-16]. This inhibits the production of superoxide anion through a negative feedback 
effect on NOX, which ultimately leads to the decrease of free radicals derived from superoxide, including hypochlorite [14]. Thus the negative feedback inhibition of NOX is resolved, and this again results in increased superoxide generation. Indomethacin treatment, on the other hand, acts the opposite way [14]. The effect of MPO and indomethacin in the actual setup probably depends greatly on the duration of treatment. In the present setting, the two-hour treatment with indomethacin did not cause significant changes, while MPO increased bactericidal activity. The five-day indomethacin treatment of rats diminished bactericidal activity, probably by decreasing hypochlorite anion concentration. According to our hypothesis mentioned above, this might lead to enhanced superoxide anion levels through the inhibition of the negative feedback and thus bactericidal activity would increase as well. However, this potential regulating mechanism could not reach the level of increased bactericidal activity, because the diminished hypochlorite concentration in the early phase determined the prognosis of the infection.

Antioxidant steroid hormones seem to improve bactericidal activity in the short run. In the long run, however, higher hypochlorite levels produced by increased MPO activity may exhibit negative feedback on NOX, leading to decreased superoxide generation and bactericidal activity. Impaired immunity is a known consequence of chronic steroid overproduction or treatment [34].

It is important to note that our results in the two experimental models are difficult to compare, one being an ex vivo, the other an in vivo setup. As detailed above, sex steroids play a role in a number of innate and acquired immune functions and a variety of immune cell types have sex steroid receptors $[23,24,26,28]$. The improved bactericidal activity of PMNs by estradiol confirmed by our present experiment is just one of these effects, and in vivo more complex processes are modulated by sex steroids.

The low number of samples in both the ex vivo and in vivo experiments is a limitation of our study, so our findings need further confirmation with greater sample numbers in the future.

\section{Conclusions}

In our experimental models MPO, estradiol, and hydrocortisone improve bacterial killing activity of PMNs. Indomethacin treatment and castration weaken immune responses and the clinical state of infected rats. These experiments did not confirm the supposed beneficial effect of indomethacin in the treatment of septic patients. On the other hand, testosterone, and even more so estradiol had a beneficial effect in bacterial infection. This finding needs further confirmation with greater sample sizes, but based on our results, it is possible, that short term adjuvant steroid treatment might have a beneficial effect in the treatment of bacterial infections and sepsis. In order to avoid side effects of steroid hormone treatment, it would be reasonable to design an endocrinologically inactive synthetic compound with the antioxidant features of the analysed steroids.

\section{Competing interests}

This study was funded by Gedeon Richter Plc.

\section{Authors' contributions}

JS participated in the writing of the manuscript, planning of the study, collection of the data and the analysis of results. ZV carried out animal treatments and bacteria reisolations and participated in the writing of the manuscript. AG carried out the ex vivo experiments and participated in the writing of the manuscript. PV carried out laboratory measurements in the in vivo experiments and participated in the writing of the manuscript. DS carried out the anaesthesia and section of rats. IM participated in the design of the study and the collection of data. SV participated in the design of the study and the analysis of results. ED participated in the design of the study and performed the statistical analysis. TM participated in the animal treatments, supervised the study and gave institutional support. ZT supervised the study and gave institutional support. BS supervised the study and participated in the analysis of results. KN participated in the ex vivo experiments, supervised the study and gave institutional support. KR supervised the study and gave institutional support. GB planned study concept and design, analyzed and interpreted data and revised the manuscript. All authors read and approved the final manuscript.

\section{Acknowledgements}

The authors are grateful to Gedeon Richter Plc. who gave financial support.

\section{Author details}

${ }^{1}$ Faculty of Medicine, 2nd Department of Internal Medicine, Semmelweis University, 46. Szentkiralyi u., H-1088 Budapest, Hungary. ${ }^{2}$ Hungarian Academy of Sciences, Institute for Veterinary Medical Research, 21. Hungaria krt., H-1143 Budapest, Hungary. ${ }^{3}$ Faculty of Medicine, Institute of Medical Microbiology, Semmelweis University, 4. Nagyvarad ter, H-1089 Budapest, Hungary. ${ }^{4}$ Department and Clinic of Internal Medicine, Szent Istvan University, Faculty of Veterinary Science, 2. Istvan u., H-1078 Budapest, Hungary. ${ }^{5}$ Faculty of Medicine, Institute of Patophysiology, Semmelweis University, 4. Nagyvarad ter, H-1089 Budapest, Hungary. ${ }^{6}$ Faculty of Medicine, 2nd Department of Obstetrics and Gynecology, Semmelweis University, 78/a Ulloi ut, H-1082 Budapest, Hungary. ${ }^{7}$ Faculty of Health and Public Services, Institute of Health Informatics Development and Further Training, Semmelweis University, 78/b Ulloi ut, H-1082 Budapest, Hungary.

Received: 14 April 2014 Accepted: 28 June 2014

Published: 7 July 2014

\section{References}

1. Winterbourn CC, Kettle AJ: Redox reactions and microbial killing in the neutrophil phagosome. Antioxid Redox Signal 2013, 18:642-660.

2. Babior BM: Phagocytes and oxidative stress. Am J Med 2000, 109:33-44

3. Gil Del Valle L: Oxidative stress in aging: Theoretical outcomes and clinical evidences in humans. Biomed Aging Pathol 2011, 1:1-7.

4. Békési G, Kakucs R, Várbíró S, Rácz K, Sprintz D, Fehér J, Székács B: In vitro effects of different steroid hormones on superoxide anion production of human neutrophil granulocytes. Steroids 2000, 65:889-894.

5. Kumar S, Lata K, Mukhopadhyay S, Mukherjee TK: Role of estrogen receptors in pro-oxidative and anti-oxidative actions of estrogens: a perspective. Biochim Biophys Acta 2010, 1800:1127-1135.

6. An KW, Kim NN, Shin HS, Kil G-S, Choi CY: Profiles of antioxidant gene expression and physiological changes by thermal and hypoosmotic stresses in black porgy (Acanthopagrus schlegeli). Comp Biochem Physiol A Mol Integr Physiol 2010, 156:262-268.

7. Goncharova ND, Shmaliy AV, Bogatyrenko TN, Koltover VK: Correlation between activity of antioxidant enzymes and circadian rhythms of corticosteroids in Macaca mulatta monkeys of different age. Exp Gerontol 2006, 41:778-783. 
8. Long F, Wang Y-X, Liu L, Zhou J, Cui R-Y, Jiang C-L: Rapid nongenomic inhibitory effects of glucocorticoids on phagocytosis and superoxide anion production by macrophages. Steroids 2005, 70:55-61.

9. Marumo T, Schini-kerth VB, Brandes RP, Busse R: Glucocorticoids Inhibit Superoxide Anion Production and p22 Phox mRNA Expression in Human Aortic Smooth Muscle Cells. Hypertension 1998, 32:1083-1088.

10. Ahlbom E, Prins GS, Ceccatelli S: Testosterone protects cerebellar granule cells from oxidative stress-induced cell death through a receptor mediated mechanism. Brain Res 2001, 892:255-262.

11. Chainy GB, Samantaray S, Samanta L: Testosterone-induced changes in testicular antioxidant system. Andrologia 1997, 29:343-349.

12. Prasad S, Kalra N, Shukla Y: Modulatory effects of diallyl sulfide against testosterone- induced oxidative stress in Swiss albino mice. Asian $J$ Androl 2006, 8:719-723.

13. Jandl RC, André-Schwartz J, Borges-DuBois L, Kipnes RS, McMurrich BJ, Babior BM: Termination of the respiratory burst in human neutrophils. J Clin Invest 1978, 61:1176-1185.

14. Békési G, Kakucs R, Sándor J, Sárváry E, Kocsis I, Sprintz D, Várbíró S, Magyar Z, Hrabák A, Fehér J, Székács B: Plasma concentration of myeloperoxidase enzyme in pre- and post-climacterial people: related superoxide anion generation. Exp Gerontol 2001, 37:137-148.

15. Békési G, Kakucs R, Varbiro S, Feher J, Pazmany T, Magyar Z, Sprintz D, Szekacs B: Induced myeloperoxidase activity and related superoxide inhibition during hormone replacement therapy. BJOG 2001, 108:474-481.

16. Jansson G: Oestrogen-induced enhancement of myeloperoxidase activity in human polymorphonuclear leukocytes-a possible cause of oxidative stress in inflammatory cells. Free Radic Res Commun 1991, 14:195-208.

17. Shacter E, Lopez RL, Pati S: Inhibition of the myeloperoxidase- $\mathrm{H} 2 \mathrm{O} 2-\mathrm{Cl}$ system of neutrophils by indomethacin and other non-steroidal anti-inflammatory drugs. Biochem Pharmacol 1991, 41:975-984

18. Moshage HJ, Janssen JA, Franssen JH, Hafkenscheid JC, Yap SH: Study of the molecular mechanism of decreased liver synthesis of albumin in inflammation. J Clin Invest 1987, 79:1635-1641.

19. Black S, Kushner I, Samols D: C-reactive Protein. J Biol Chem 2004 279:48487-48490.

20. Marnell L, Mold C, Du Clos TW: C-reactive protein: ligands, receptors and role in inflammation. Clin Immunol 2005, 117:104-111.

21. De Oliveira AT, da Silva TG, de Souza FE, Rezende Leite AC, de Moraes SRA, de Sousa Maia MB: Impact of early malnourishment on the chronic inflammatory response and its implications for the effect of indomethacin on Wistar rats. Br J Nutr 2011, 106:845-851.

22. Sasaki M, Fujii $Y$, Iwamoto M, Ikadai H: Effect of sex steroids on Babesia microti infection in mice. Am J Trop Med Hyg 2013, 88:367-375.

23. Snider H, Lezama-Davila C, Alexander J, Satoskar AR: Sex hormones and modulation of immunity against leishmaniasis. Neuroimmunomodulation 2009, 16:106-113.

24. Angele MK, Schwacha MG, Ayala A, Chaudry $1 \mathrm{H}$ : Effect of gender and sex hormones on immune responses following shock. Shock 2000, 14:81-90.

25. Olsen NJ, Kovacs WJ: Gonadal steroids and immunity. Endocr Rev 1996, 17:369-384.

26. Watanuki H, Yamaguchi T, Sakai M: Suppression in function of phagocytic cells in common carp Cyprinus carpio L. injected with estradiol, progesterone or 11-ketotestosterone. Comp Biochem Physiol C Toxicol Pharmacol 2002, 132:407-413.

27. Zhang H, Bain JL, Caskey CP, Sandifer LC, Johnson RB: Effects of gender on serum biomarkers of systemic inflammation coincident to experimentally-induced periapical lesions. Arch Oral Biol 2011, 56:168-176.

28. Gee AC, Sawai RS, Differding J, Muller P, Underwood S, Schreiber MA: The influence of sex hormones on coagulation and inflammation in the trauma patient. Shock 2008, 29:334-341.

29. Straub RH: The complex role of estrogens in inflammation. Endocr Rev 2007, 28:521-574.

30. Biswas DK, Singh S, Shi Q, Pardee AB, Iglehart JD: Crossroads of estrogen receptor and NF-kappaB signaling. Sci STKE 2005, 2005:pe27.

31. Roth JA, Kaeberle ML, Hsu WH: Effect of estradiol and progesterone on lymphocyte and neutrophil functions in steers. Infect Immun 1982 35:997-1002.
32. Kita E, Takahashi S, Yasui K, Kashiba S: Effect of estrogen (17 beta-estradiol) on the susceptibility of mice to disseminated gonococcal infection. Infect Immun 1985, 49:238-243.

33. Klebanoff SJ: Effect of estrogens on the myeloperoxidase-mediated antimicrobial system. Infect Immun 1979, 25:153-156.

34. Würzburger MI, Prelevic GM, Brkic SD, Vuckovic S, Pendic B: Cushing's syndrome - transitory immune deficiency state? Postgrad Med J 1986, 62:657-659.

doi:10.1186/1476-0711-13-27

Cite this article as: Stark et al:: The effect of indomethacin,

myeloperoxidase, and certain steroid hormones on bactericidal activity: an ex vivo and in vivo experimental study. Annals of Clinical Microbiology and Antimicrobials 2014 13:27.

\section{Submit your next manuscript to BioMed Central and take full advantage of:}

- Convenient online submission

- Thorough peer review

- No space constraints or color figure charges

- Immediate publication on acceptance

- Inclusion in PubMed, CAS, Scopus and Google Scholar

- Research which is freely available for redistribution

Submit your manuscript at www.biomedcentral.com/submit 